\title{
Knowledge, attitudes, and practices of breastfeeding among women visiting primary healthcare clinics on the island of Abu Dhabi, United Arab Emirates
}

\author{
Mai Isam Al Ketbi ${ }^{1 *} \mathbb{D}$, Sultan Al Noman ${ }^{1}$ Abdelqadir Al Ali, Ebtihal Darwish², Maha Al Fahim ${ }^{1}$ and Jaishen Rajah ${ }^{1}$
}

\begin{abstract}
Background: The World Health Organization recommends continued breastfeeding up to 2 years of age or beyond. This study assessed breastfeeding knowledge, attitudes, and practices among women residing on the island of Abu Dhabi and identified associated factors.

Methods: We conducted a cross-sectional study using a self-administered questionnaire among mothers visiting primary healthcare clinics in Abu Dhabi between November 2014 and 2015. Participants were women aged at least 18 years who had at least one child aged 2 years or younger at the time of the study. Breastfeeding knowledge, attitudes, and practices were assessed on the basis of experience with last child. Selected questions were used to develop a scaled scoring system to categorize these aspects as good, fair, or poor. Exclusive breastfeeding is defined as the act of feeding infants only breast milk since birth, without providing water, formula, or other liquid supplements.
\end{abstract}

Results: The participants were 344 women. Exclusive breastfeeding for 6 months was reported by only 46 (16.9\%, $95 \% \mathrm{Cl} 0.10,0.17, n=272) .79(28.7 \%, n=275)$ of the participants were breastfeeding and planning to continue after the child was $\geq 24$ months. Multivariate logistic regression analysis revealed that the following factors were associated with exclusive breastfeeding: mothers with female children (adjusted OR [AOR] 2.42; 95\% Cl 1.18, 4.97) and better breastfeeding knowledge scores (AOR 1.25; $95 \% \mathrm{Cl} 1.04,1.50)$. The following factors were associated with less likelihood of exclusively breastfeeding: working mothers (AOR 0.29; $95 \% \mathrm{Cl} 0.12,0.72$ ), living with relatives (AOR $0.21 ; 95 \% \mathrm{Cl} 0.05,0.81$ ), no past exclusive breastfeeding experience (AOR $0.23 ; 95 \% \mathrm{Cl} 0.09,0.58$ ) and being offered readymade liquid formula in hospital (AOR $0.33 ; 95 \% \mathrm{Cl} 0.15,0.72$ ). The most common reason for stopping breastfeeding was insufficient breast milk production (68/89, 76\%), and the most common work related reason was inadequate maternity leave (24/89, 15\%).

Conclusion: Although breastfeeding knowledge was generally good, breastfeeding practice was still suboptimal. Modifiable factors found to predict exclusive breastfeeding included breastfeeding knowledge and mothers' employment status.

Keywords: Abu Dhabi Island, U.A.E., Breastfeeding knowledge, Breastfeeding attitude, Breastfeeding practice, Breastfeeding duration, Reasons for stopping breastfeeding, Breastfeeding, Exclusive breastfeeding, Primary healthcare clinics

\footnotetext{
*Correspondence: maalketbi@seha.ae; maialketbi89@gmail.com

${ }^{1}$ Sheikh Khalifa Medical City (SKMC), P.O. Box: 51900, Abu Dhabi, United Arab

Emirates

Full list of author information is available at the end of the article
}

(c) The Author(s). 2018 Open Access This article is distributed under the terms of the Creative Commons Attribution 4.0 International License (http://creativecommons.org/licenses/by/4.0/), which permits unrestricted use, distribution, and reproduction in any medium, provided you give appropriate credit to the original author(s) and the source, provide a link to the Creative Commons license, and indicate if changes were made. The Creative Commons Public Domain Dedication waiver (http://creativecommons.org/publicdomain/zero/1.0/) applies to the data made available in this article, unless otherwise stated. 


\section{Background}

The importance of breastfeeding for both infants and mothers are globally recognized [1]. Exclusive breastfeeding is defined as the act of feeding the infant only breast milk, with no supplemental liquids or solids except for liquid medicine or vitamin/mineral supplements [2]. During the first 6 months of life, breast milk alone is the ideal nourishment for infants, providing all the necessary nutrients, including vitamins and minerals [3].

The American Academy of Pediatrics (AAP) recommends exclusive breastfeeding for 6 months and continued breastfeeding for at least 12 months; thereafter, it can be continued for as long as the mother and the baby desire [1]. The World Health Organization (WHO) recommends continued breastfeeding up to 2 years of age or beyond [4] and it has been estimated that optimal breastfeeding of children younger than 2 years, could annually save the lives of over 800,000 children under 5 years of age [4].

Using data from 66 countries, a review of the differences in the prevalence of exclusive breastfeeding among infants younger than 6 months between 1995 and 2010 revealed that the prevalence of exclusive breastfeeding among infants of this age group in developing countries increased from 33\% in 1995 to merely 39\% in 2010 [5]. Despite considerable improvements in some regions, the prevalence of exclusive breastfeeding remains far too low in many areas of the developing world [5].

The knowledge, attitudes, and practices among women regarding breastfeeding vary in different countries. In the United Arab Emirates (U.A.E.), a recent study involving 593 Emirati mothers showed that the feeding practices of infants and young children were suboptimal [6]. Although almost all the mothers in the study had initiated breastfeeding (98\%), only $25 \%$ of the infants had been exclusively breastfed since birth at 6 months of age [6]. In another prospective study conducted in Sharjah, U.A.E. [7], a sample of 221 women who gave birth at $\mathrm{Al}$ Qassimi Hospital were surveyed regarding breastfeeding patterns at 1 day, 1 month, and 6 months postpartum; the corresponding exclusive breastfeeding rates since birth were $76.5,48.4$, and $13.3 \%$, respectively [7]. Unfortunately, local data on the knowledge, attitudes, and practices among women regarding breastfeeding are limited.

In Saudi Arabia, a recent cross-sectional study on school teachers in the Abha female educational district showed that out of 384 women, 31\% started breastfeeding their children within 1 hour of delivery, while only 8.3\% reported exclusive breastfeeding for 6 months [8]. Regarding their knowledge, although $89.3 \%$ of the participants reported that colostrum is good for the baby, there was a low rate of knowledge regarding the appropriate duration of exclusive breastfeeding: only $28 \%$ of the participants chose 6 months as the answer, and this might explain the low rate of exclusive breastfeeding at
6 months [8]. Regarding their attitudes, the most important reason given by the participants for initiating breastfeeding was their Islamic religious background (56.6\%), which was practiced by all of them [8].

In January 2014, the Federal National Council's (FNC) Health, Labour and Social Affairs committee proposed adding a breastfeeding clause to the U.A.E.'s Child Rights Law, which would make breastfeeding a mandatory requirement for mothers of all children up to the age of 2 years as breastfeeding is crucial for a child's development [9]. This proposed breastfeeding clause has not yet been officially passed. Fortunately, a new law extending fully paid maternity leave from 2 months to 3 months was recently established and passed in the U.A.E., which is a step in the right direction [10]. However, there is more to be done since this law is applied to government entities only and hence not all private companies have chosen to implement this new policy $[10,11]$.

Despite WHO recommendations, it was observed that not many women in the U.A.E were breastfeeding exclusively for 6 months since birth of the infant $[6,7]$. Since there is limited local data on the knowledge and attitudes of women toward breastfeeding in the U.A.E., research in this field is vital to explore the knowledge, attitudes, and practices regarding breastfeeding among women and to explore any possible barriers to exclusive breastfeeding so as to develop strategies for raising awareness, overcome any barriers, and improve breastfeeding rates. Therefore, the aim of our study is to assess breastfeeding knowledge, attitudes, and practices among women residing in Abu Dhabi and to identify factors that influence these aspects of breastfeeding.

\section{Methods}

\section{Study setting and population}

This cross-sectional study was conducted among mothers visiting four primary healthcare clinics, Bateen, Zafaranah, Khaleej, and Rowda, in Abu Dhabi between November 2014 and November 2015 using a self-administered questionnaire.

The target study population was composed of women aged 18 years or older, regardless of nationality, who had at least one child aged 2 years or younger at the time of the study. We excluded women who were non-English or non-Arabic speakers. The estimated target population size was 4470 , based on the clinics' attendance records during January. Based on the null hypothesis that $13 \%$ of population is exclusively breastfeeding for 6 months, the sample size was calculated using a 95\% confidence interval (Newcombe formula) and was found to be 354 mothers (http://www.surveysystem.com/sscalc.htm) [12, 13].

The self-administered questionnaires were then proportionally distributed to the four primary health care clinics based on the number of patients attending each clinic 
from the total sample size. At each clinic, questionnaires were distributed to women who met the inclusion and exclusion criteria in a convenience non-random collection sampling until the required numbers were attained. The aim was to assess the participants' breastfeeding knowledge, attitudes, and practices on the basis of their experience with their last child. In this study, exclusive breastfeeding was defined as feeding of infants with only breast milk since birth, with no water, formula or liquid supplements.

\section{Study instrument}

Given the absence of a validated standardized questionnaire, the questionnaire used in the present study was adapted from a similar study that was conducted in Saudi Arabia [8] and modified to meet our objectives.

The resulting self-administered questionnaire contained a total of 50 questions and was divided into four parts that addressed the participants' sociodemographic characteristics (13 questions) and breastfeeding knowledge (13 questions), attitudes (7 questions), and practices (13 questions). The majority of the questions were based on the participants' experience with their last child unless otherwise specified. Selected questions under breastfeeding knowledge (12 questions), attitudes (6 questions), and practices (10 questions) were used to develop a scaled scoring system to categorize these aspects as good, fair, or poor. Each correct or favourable answer chosen by participants was given one or two points; then the points were summed for each participant. No points were deducted for wrong or unfavourable answers. The participants' scoring system was as follows:

- Knowledge: Good (8-12 points), Fair (4-7 points), Poor (0-3 points)

- Attitude: Good (5-6 points), Fair (3-4 points), Poor (0-2 points)

- Practice: Good (4-10 points), Fair (2-3 points), Poor (0-1 point)

Questions intended to assess breastfeeding knowledge included the average number of feedings a child should receive per day, duration of breastfeeding from each breast, importance of colostrum, benefits of breastfeeding to the child and the mother, age up to which the child should receive breast milk, age at which the mother should start supplementary food, whether breast milk alone is better than formula milk to fulfill the child's necessary dietary requirements, sufficiency of breast milk alone during the first 6 months of life, relationship between breastfeeding and the mother's weight, whether breast milk loses its benefits when it is pumped, and storage duration for pumped breast milk at room temperature and in a refrigerator.
Questions intended to assess breastfeeding attitudes included the reasons for adopting breastfeeding, participant self-image (weight and hair loss), whether breast milk loses its benefits when it is pumped, whether breastfeeding should be stopped because of medications, intention to breastfeed future children, and intention to participate in classes related to breastfeeding for future pregnancies.

Questions intended to assess breastfeeding practices included the child's age at which breastfeeding was stopped, reasons for stopping breastfeeding before the child reached 2 years of age, time of breastfeeding initiation after delivery, duration of exclusive breastfeeding since birth, age of starting formula and other supplements, whether the child was given ready-made liquid formula in the hospital, and whether the mother attended classes related to breastfeeding during pregnancy. Questions used to measure exclusive breastfeeding since birth among participants included:

- For how long did you exclusively breastfeed (giving your child only breast milk, no formula milk or food) your last child since birth?

- If you are still exclusively breastfeeding (giving your child only breast milk, no formula milk or food) your last child, until what age are you planning to continue?

Informed consent forms were attached with each questionnaire for the participants to read and sign if they were willing to participate in the study. Questionnaires and informed consent forms were drafted in English and Arabic. A pilot study was conducted after ethical approval was granted in order to assess the questionnaire's comprehensibility, and modifications were accordingly made. The pilot sample met this study's inclusion and exclusion criteria and the pilot sample size was 15 .

The charge nurses positioned at the four primary healthcare clinics were briefed regarding the questions included in the questionnaire and given training regarding the participants' anonymity and informed consent.

\section{Data collection}

Questionnaires were printed and then proportionally distributed to the four primary healthcare clinics in Abu Dhabi. The charge nurse at each clinic was requested to distribute the questionnaires randomly to patients who matched our inclusion criteria. After the completion of the questionnaires by the participants, the charge nurses collected and sealed the questionnaires in envelopes to ensure the participants' confidentiality. After the end of the study period, the charge nurses were requested to return the completed questionnaires to the authors. On the basis of the participants' responses, their knowledge, attitudes, and practices of breastfeeding were assessed. 


\section{Data analysis}

After the collection of the questionnaires, the obtained data were organized using the MS Excel software program, coded, and analyzed using the Statistical Package for Social Sciences (SPSS) version 16. Means and standard deviation (SD) were used for numerical data, whereas percentages were used for categorical data.

First, chi squared $\left(\chi^{2}\right)$ test was conducted to assess the effect of certain factors on breastfeeding knowledge, attitudes, and practices (specifically exclusive breastfeeding). Factors that were analyzed in this study included: mother's age, mother's educational background, mother's employment status, employment sector, entitlement to breastfeeding hours by employer, living with husband and children only or along with relatives, number of housemaids or nannies, monthly family income, number of children, gender of last child, last child's gestational age at delivery, mode of delivery of last child, healthcare provider explained the importance of breastfeeding during antenatal visits for last pregnancy, healthcare provider explained the importance of breastfeeding after delivery of last child, healthcare provider explained the appropriate practices of breastfeeding for last child, past breastfeeding experience and past exclusive breastfeeding experience.

Second, association between the dependent variable (exclusive breastfeeding for 6 months $=1$ or not $=0$ ) and independent variables was estimated in multivariate logistic regression analysis using MedCalc Statistical Software version 18 (MedCalc Software bvba, Ostend, Belgium; http:// www.medcalc.org; 2018). The number of variables selected in our study is based on the recommendations of approximately ten variables per event to prevent bias in both directions $[14,15]$. Adjusted odds ratio (AOR) with 95\% confidence interval (CI) were computed and a $p$ value less than 0.05 was selected as the cutoff for statistical significance.

\section{Results}

A total of 354 questionnaires were distributed, but only 344 participants returned completed questionnaire copies, yielding a response rate of $97 \%$.

\section{Description and characteristics of participants Mother-related}

Most of the participants in the study sample were aged 25-29 years (37.5\%), had 2-4 children (60.6\%) had university or higher educational degrees (80\%), and the mean (SD) duration of past breastfeeding experience was 16.2 months $( \pm 7.3)$ (Tables 1 and 2).

\section{Family and child -related}

The majority of the participants had a monthly family income of 15,000-30,000 U.A.E. dirham (AED; 46.9\%) (Table 1). The median (IQR) number of people living in the participants' houses (including housemaids, drivers, etc.) was $4( \pm 2)$ (Table 2$)$. The mean (SD) age of the participants' last child was 8.2 months $( \pm 5.7)$, and the mean (SD) breastfeeding duration of that child was 7.1 months ( \pm 5.4) (Table 2).

\section{Employer-related}

The majority of the participants were entitled to breastfeeding hours by their employer (82.2\%) (Table 1). The mean (SD) employer-entitled breastfeeding hours per day was $1.1 \mathrm{~h}( \pm 0.3)$, and the mean (SD) duration of the right to these employer-entitled breastfeeding hours was 15.3 months $( \pm 5.2)$ (Table 2$)$.

\section{Mothers' breastfeeding knowledge}

A total of 176 (51.2\%) mothers were found to have good breastfeeding knowledge, 149 (43.3\%) had fair knowledge, and only 19 (5.5\%) had poor knowledge (Table 3). Among the mothers, $273(81.2 \%)$ reported that breast milk is sufficient for a child in the first 6 months of life and 290 (86.1\%) reported that complementary food should be introduced at 6 months of age. A total of 114 (33.9\%) mothers reported that a child should receive breast milk for at least 24 months of age (Table 3). The most common sources of information regarding breastfeeding for participants were family $(66.5 \%)$, doctors (58.5\%), nurses/midwives (50.1\%), and the Internet (40.7\%) (Table 3).

\section{Factors affecting mothers' breastfeeding knowledge}

Better breastfeeding knowledge was seen among mothers with university or higher educational background $(p=0.001)$, those who were employed $(p=0.001)$, those who lived with their husband and children along with relatives $(p=0.000)$, those who adopted breastfeeding because of their mother or mother-in-law's encouragement $(p=0.005)$, those with a monthly family income of more than 30,000 AED $(p=0.011)$, and those who only had one child ( $p=0.016)$ (Additional file 1).

Statistically significant correlations were also found between better breastfeeding knowledge and having given birth to the last child at 37 weeks or more $(p=0.003)$, having received advice from a healthcare provider about the importance of breastfeeding during antenatal $(p=0.049)$ or postnatal visits $(p=0.001)$, having been counseled about the appropriate breastfeeding practices at any time $(p=$ $0.000)$, having past breastfeeding experience $(p=0.002)$ (Additional file 1).

\section{Mothers' breastfeeding attitude}

Only $72(20.9 \%)$ mothers were found to have a good breastfeeding attitude, 182 (52.9\%) had a fair attitude, and $90(26.2 \%)$ had a poor attitude (Table 4). A total of 307 (92.8\%) mothers reported a positive attitude in the form of 
Table 1 Selected characteristics of the participants in the study sample $(n=344)$

\begin{tabular}{lll}
\hline Variable & Number & $(\%)$ \\
\hline Age (in years) & & \\
$18-24$ & 39 & $(11.4)$ \\
$25-29$ & 128 & $(37.5)$ \\
$30-34$ & 107 & $(31.4)$ \\
$35-39$ & 57 & $(16.7)$ \\
$40-44$ & 10 & $(3)$ \\
$\geq 45$ & 0 & $(0)$
\end{tabular}

Marital status

Married

Divorced

Widowed

Educational background

Primary school or lower

Secondary school

(0.9)

University or higher

Employed

No
Yes
Self-employed
Employment sector
Private

Entitled to breastfeeding hours by employer

$$
\text { Yes }
$$$$
\text { No }
$$

Living with husband and children only

Yes
No (Living with relatives)
No (Separated/Divorced/Widowed)
Number of housemaids or nannies

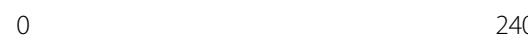

$1 \quad 70$

$>1$

18

Monthly family income (in AED)

$$
\begin{aligned}
& <15,000 \\
& 15,000-30,000
\end{aligned}
$$

$>30,000$

Number of children

$$
\text { 2-4 }
$$$$
\geq 5
$$

Table 1 Selected characteristics of the participants in the study sample $(n=344)$ (Continued)

\begin{tabular}{lll}
\hline Variable & Number & $(\%)$ \\
\hline Gender of last child & 169 & $(51.4)$ \\
$\quad$ Male & 160 & $(48.6)$ \\
$\quad$ Female & & \\
Last child's gestational age at delivery & 69 & $(20.5)$ \\
$\quad<37$ weeks & 267 & $(79.5)$ \\
$\geq 37$ weeks & & \\
Mode of delivery of last child & 196 \\
$\quad$ Vaginal delivery & 144
\end{tabular}

Healthcare provider explained the importance of breastfeeding during antenatal visits for last pregnancy

$\begin{array}{lll}\text { Yes } & 275 \\ \text { No } & 62 & \text { (81.6) }\end{array}$

Healthcare provider explained the importance of breastfeeding after delivery of last child

$\begin{array}{lll}\text { Yes } & 286 \\ \text { No } & 53\end{array}$

Healthcare provider explained the appropriate practices of breastfeeding for last child

$\begin{array}{lll}\text { Yes } & 268 & (79.8) \\ \text { No } & 68 & \text { (20.2) }\end{array}$

an intention to breastfeed future children and 219 (66.6\%) planned to attend breastfeeding classes for future pregnancies (Table 4). As reasons for adopting breastfeeding, most of the participants reported child health (89.8\%), religious background (37\%), and cleanliness and easy preparation (31.6\%) (Table 4).

\section{Factors affecting mothers' breastfeeding attitude}

Better breastfeeding attitudes were observed among mothers in 35-39 years age group $(p=0.003)$, those employed in the private sector $(p=0.017)$, and those who gave birth to their last child at 37 weeks or later $(p=0.005)$ (Additional file 2).

Statistically significant correlations were also found between better breastfeeding attitudes and living with a husband and children along with other relatives $(p=0.014)$, having one maid or nanny $(p=0.016)$, and having a monthly family income of $15,000-30,000$ AED $(p=0.005)$ (Additional file 2).

\section{Mothers' breastfeeding practice}

Only 94 (27.8\%) mothers were found to adopt good breastfeeding practices, 129 (38.2\%) adopted fair practices, and 115 (34\%) adopted poor practices (Table 5). Although a high percentage of mothers had breastfed their last child for any duration of time (84.4\%), had 
Table 2 Participants' characteristics in the study sample: Mean $( \pm$ SD) and Median $( \pm \mathrm{IQR})(n=344)$

\begin{tabular}{|c|c|c|}
\hline Variable & Mean $\left( \pm S D^{a}\right)$ & Median $\left( \pm \mid Q^{b}\right.$ \\
\hline Number of people living inside house (Including housemaids, drivers, etc.) & $4.7( \pm 2.9)$ & $4( \pm 2)$ \\
\hline Age of last child (in months) & $8.2( \pm 5.7)$ & $6( \pm 8)$ \\
\hline Employer-entitled breastfeeding hours per day (in hours) & $1.1( \pm 0.3)$ & $1( \pm 1)$ \\
\hline Employer-entitled breastfeeding hours duration (in months) & $15.3( \pm 5.2)$ & $18( \pm 6)$ \\
\hline Breastfeeding duration of previous children (in months) $(n=171)$ & $16.2( \pm 7.3)$ & $17( \pm 12)$ \\
\hline Age of stopping breastfeeding of last child (in months) $(n=66)$ & $7.1( \pm 5.4)$ & $6( \pm 9)$ \\
\hline
\end{tabular}

${ }^{\mathrm{a}} \mathrm{SD}$ Standard deviation, ${ }^{\mathrm{b}}$ IQR Interquartile range

no difficulties in breastfeeding their last child (82.1\%), and had past breastfeeding experience and exclusive breastfeeding experience (56.9 and $39.4 \%$, respectively), it was noted that only 79 (28.7\%) mothers were currently breastfeeding their last child at the time of the study and were intending to continue at least until the child reached 24 months of age. Only 46 (16.9\%) (95\% CI
$0.10,0.17)[16]$ mothers had exclusively breastfed their last child for 6 months and only eight (2.9\%) were planning to continue exclusive breastfeeding until the child reached 6 months of age (Table 5).

Feeding practices for the last child were also studied, and it was found that mothers had introduced water, herbal supplements, formula milk, and food at early

Table 3 Breastfeeding knowledge of participants visiting four primary healthcare clinics in Abu Dhabi $(n=344)$

\begin{tabular}{|c|c|c|}
\hline Variable & Number & (\%) \\
\hline \multicolumn{3}{|l|}{ Correctly answered breastfeeding knowledge questions by participants (total of 12 scored questions): } \\
\hline Breastfeeding child $\geq 8$ times/day during the first month & 179 & $(53.1)$ \\
\hline Breastfeeding duration $\geq 15$ min from each breast during the first month & 116 & (34.6) \\
\hline Colostrum is good for child & 289 & (86) \\
\hline Breastfeeding is beneficial for both the mother and the child & 315 & (94) \\
\hline Children should receive breast milk until $\geq 24$ months of age & 114 & (33.9) \\
\hline Complementary food should be introduced at 6 months of age & 290 & $(86.1)$ \\
\hline Breast milk is superior to formula milk in fulfilling child's necessary dietary requirements & 323 & $(96.1)$ \\
\hline Breast milk is sufficient for child in the first 6 months of life & 273 & $(81.2)$ \\
\hline Breastfeeding decreases the mother's weight & 193 & (57.3) \\
\hline Breast milk does not lose its benefits when it is pumped out or stored & 184 & (55.6) \\
\hline Pumped breast milk can be stored at room temperature $\left(60^{\circ} \mathrm{F}-85^{\circ} \mathrm{F} / 15.5^{\circ} \mathrm{C}-29.4^{\circ} \mathrm{C}\right)$ for up to 8 hours & 160 & $(47.5)$ \\
\hline Pumped breast milk can be stored in the refrigerator $\left(39^{\circ} \mathrm{F}\right.$ or colder $/ 3.99^{\circ} \mathrm{C}$ or colder) for up to 8 days & 99 & (29.6) \\
\hline \multicolumn{3}{|l|}{ Participants' overall knowledge level: } \\
\hline Good & 176 & $(51.2)$ \\
\hline Fair & 149 & (43.3) \\
\hline Poor & 19 & $(5.5)$ \\
\hline \multicolumn{3}{|l|}{ Participants' sources of information about breastfeeding: } \\
\hline Doctors & 197 & (58.5) \\
\hline Nurses/midwives & 169 & $(50.1)$ \\
\hline Friends & 111 & (32.9) \\
\hline Family & 224 & (66.5) \\
\hline TV programs & 80 & (23.7) \\
\hline Campaigns & 51 & $(15.1)$ \\
\hline Magazines & 49 & $(14.5)$ \\
\hline Breastfeeding classes & 52 & $(15.4)$ \\
\hline Internet & 137 & $(40.7)$ \\
\hline Others & 11 & (3.3) \\
\hline
\end{tabular}


Table 4 Breastfeeding attitudes of participants visiting four primary healthcare clinics in Abu Dhabi $(n=344)$

\begin{tabular}{lll}
\hline Variable & Number & $(\%)$ \\
\hline
\end{tabular}

Response of participants to breastfeeding attitude questions (Total of six scored questions)

Breastfeeding can increase the mother's weight:

Agree
Neutral

Disagree $^{a}$

One of the causes of hair loss is breastfeeding:

$\begin{array}{ll}\text { Agree } & 114 \\ \text { Neutral } & 74\end{array}$

Pumping breast milk makes it no longer beneficial for the child:

$\begin{array}{ll}\text { Agree } & 39 \\ \text { Neutral } & 89\end{array}$

Disagree $^{a}$

89

205

Mothers should stop breastfeeding if they take any type of medication:

$\begin{array}{lll}\text { Agree } & 138 \\ \text { Neutral } & 105 & (41.8) \\ \text { Disagree }^{a} & 87 & \text { (26.4) }\end{array}$

Intention to breastfeed future children:

$\begin{array}{ll}\text { Agree }^{a} & 307 \\ \text { Neutral } & 15 \\ \text { Disagree } & 9\end{array}$

Plan to attend breastfeeding classes in future pregnancy:

Agree $^{a}$

219

Neutral

82

Disagree

28

Overall participants' attitude level:

Good $\quad 72$

Fair

Poor

Reasons behind adoption of breastfeeding:

Religious background

Healthcare providers

Child health

Media

Cleanliness and easy preparation

Personal determination or experience

Encouragement from mother/mother-in-law

Encouragement from husband

Other

I don't know

11

(20.6)

(89.8)

${ }^{a}$ Response indicates positive attitude mean $( \pm \mathrm{SD})$ ages $(4.2 \pm 2.1,3.3 \pm 2.9,3.1 \pm 2.9$ and $6.1 \pm$ 1.7, respectively). Regarding formula milk use, 176 (58.3\%) mothers reported that their last child was not given ready-made liquid formula in the hospital, but most mothers (48\%) reported that they were advised by a doctor to start formula milk for their last child (Table 5).

Moreover, non-work related and work related reasons for stopping breastfeeding before the age of 24 months were explored and are summarized in Table 6. Among the 89 women who had stopped breastfeeding, the most common non-work related reasons that women reported were decreased milk production (76.4\%), the baby seeming hungry or unsatisfied after feeding (33.3\%), and the baby refusing to feed (21.3\%). Moreover, $15.7 \%$ of mothers reported that they stopped breastfeeding because they had to return to work. The most common work related reason for stopping breastfeeding was insufficient maternity leave, which prevented mothers from developing a breastfeeding schedule or habit (14.5\%), followed by insufficient time off during work days for breastfeeding (12\%).

\section{Factors affecting mothers' breastfeeding practice and exclusive breastfeeding}

Better breastfeeding practice was seen among mothers who delivered their last child by vaginal delivery $(p=0.003)$ and those who had past experience of exclusive breastfeeding $(p=0.009)$ (Additional file 3).

In regards to factors affecting exclusive breastfeeding practices specifically, the following were found to have a statistically significant effect on exclusive breastfeeding: mother's employment status $(p=0.004)$, living with relatives $(p=0.048)$, gender of last child $(p=0.01)$, gestation of last child $(p=0.027)$, past exclusive breastfeeding experience $(p=0.000)$ and mothers offered readymade liquid formula in hospital $(p=0.001)$. (Table 7$)$.

\section{Logistic regression analysis for factors influencing exclusive breastfeeding practices}

Factors influencing exclusive breastfeeding practices for 6 months were explored using multivariate logistic regression analysis (Table 8). Only factors that were found to have a statistically significant effect on exclusive breastfeeding in chi squared test were included in the multivariate logistic regression analysis.

The multivariate logistic regression analysis showed that working mothers $(\mathrm{AOR}=0.29 ; 95 \% \mathrm{CI} 0.12,0.72$ ), those with no past exclusive breastfeeding experience ( $\mathrm{AOR}=0.23$; 95\% CI 0.09, 0.58), those who were offered readymade liquid formula in hospital (AOR $=0.33$; $95 \%$ CI $0.15,0.72$ ) and those who lives with their relatives (AOR $=0.21 ; 95 \%$ CI $0.05,0.81)$ are less likely to exclusively breastfeed their children for 6 months. (Table 8). On the other hand, mothers with female children (AOR $=2.42 ; 95 \%$ CI 1.18, 4.97) and better breastfeeding 
Table 5 Breastfeeding practices of participants visiting four primary healthcare clinics in Abu Dhabi

\begin{tabular}{|c|c|c|c|}
\hline Variable & Number & (\%) & Sample size $(n)$ \\
\hline \multicolumn{4}{|c|}{ Positively answered breastfeeding practice questions by participants on the basis of their experience with their last child (Total of six scored questions): } \\
\hline Initiation of breastfeeding immediately and within the first hour of life & 193 & (72.6) & 266 \\
\hline Currently breastfeeding the last child and intending to continue until the age of $\geq 24$ months & 79 & $(28.7)$ & 275 \\
\hline Exclusively breastfed last child for 6 months & 46 & $(16.9)$ & 272 \\
\hline Planning to continue exclusively breastfeeding last child until 6 months of age (for children $<6$ months of age) & 8 & $(2.9)$ & 273 \\
\hline Child was not given ready-made liquid formula in the hospital & 176 & $(58.3)$ & 302 \\
\hline Attended breastfeeding classes during pregnancy & 68 & $(22.2)$ & 306 \\
\hline Participants' overall practice level & & & 338 \\
\hline Good & 94 & $(27.8)$ & \\
\hline Fair & 129 & $(38.2)$ & \\
\hline Poor & 115 & (34) & \\
\hline Breastfed last child for any duration of time & 266 & $(84.4)$ & 315 \\
\hline Had no difficulties in breastfeeding last child & 220 & $(82.1)$ & 268 \\
\hline Has past breastfeeding experience from previous children & 185 & $(56.9)$ & 325 \\
\hline Has past exclusive breastfeeding experience from previous children & 124 & $(39.4)$ & 315 \\
\hline Was advised to start formula milk for last baby by the following persons & & & 277 \\
\hline Doctor & 133 & (48) & \\
\hline Nurse & 3 & $(1.1)$ & \\
\hline Pharmacist & 8 & $(2.9)$ & \\
\hline Family member & 30 & $(10.8)$ & \\
\hline Friends & 15 & (5.4) & \\
\hline Others & 1 & $(0.4)$ & \\
\hline No one & 25 & (9) & \\
\hline
\end{tabular}

knowledge scores $(\mathrm{AOR}=1.25 ; 95 \%$ CI $1.04,1.50)$ were more likely to exclusively breastfeed their children for 6 months (Table 8).

\section{Mothers' breastfeeding knowledge, attitudes, and practices}

Mothers' breastfeeding attitude was statistically significantly affected by their breastfeeding knowledge $(p<0.001)$ (Fig. 1$)$. In addition, mothers' breastfeeding practice was also statistically significantly affected by their breastfeeding knowledge $(p=0.022)$ (Fig. 2). There was no statistically significant relationship between mothers' breastfeeding attitudes and practices.

Breastfeeding clause in the U.A.E.'s child rights law (2014) The participants' opinions about the proposed breastfeeding clause in the U.A.E.'s Child Rights Law were explored. Although only $32.3 \%$ of the participants were aware of the proposed breastfeeding clause, the majority of them agreed/strongly agreed that this clause would have a positive effect on babies (84.3\%) and disagreed/strongly disagreed that it would have a negative effect on mothers (59.6\%).

\section{Discussion}

In our study, $72.6 \%$ of the mothers complied with the WHO recommendations of starting breastfeeding within 1 hour of delivery [4, 17]; this figure was higher than that reported in a Saudi Arabian study (31\%) [8]. This difference in breastfeeding practice could reflect efforts by hospitals in Abu Dhabi to achieve baby-friendly practices and establish the ten-step initiative for successful breastfeeding as per WHO $[18,19]$.

Sustained exclusive breastfeeding for up to 6 months without any supplement was reported by $16.9 \%$ of the mothers in our study. This figure was close to that seen in another study in Saudi Arabia (15.9\%) [20] and was better than the figures reported in numerous other studies in the region $[8,21]$ as well as in the U.S.A [22, 23]. However, it was lower than that reported in studies in Uganda (49.8\%) $[24,25]$. The higher exclusive breastfeeding rate at 6 months in this study compared to Saudi Arabian studies could be explained by the fact that a higher percentage of women in our study (81.2\%) believed that breast milk alone was sufficient for the child in the first 6 months of life compared with a lower percentage $(28 \%)$ in a study in Saudi Arabia [8]. This fact was supported in our study, where it was found that mothers who had better 
Table 6 Reasons indicated by mothers who stopped breastfeeding before their children turned two $(n=89)$

\begin{tabular}{|c|c|c|}
\hline Reasons cited as important & Number & (\%) \\
\hline \multicolumn{3}{|l|}{ Lactation factors } \\
\hline Breast problem (pain, cracked nipple, etc.) & 8 & (9) \\
\hline \multicolumn{3}{|l|}{ Psychosocial factors } \\
\hline Breastfeeding was tiring & 9 & $(10.1)$ \\
\hline Felt it was time to stop & 5 & (5.6) \\
\hline Had too many household duties or other commitments & 4 & $(4.5)$ \\
\hline Difficulty finding nursing areas outside the home & 4 & $(4.5)$ \\
\hline Breastfeeding was too inconvenient & 3 & (3.4) \\
\hline Lack of husband's support & 2 & $(2.2)$ \\
\hline Family recommendation & 1 & $(1.1)$ \\
\hline Wanted or needed someone else to feed my baby & 0 & (0) \\
\hline \multicolumn{3}{|l|}{ Nutritional factors } \\
\hline Decreased milk production & 68 & $(76.4)$ \\
\hline Baby hungry/unsatisfied after feeding & 30 & (33.3) \\
\hline Baby not gaining sufficient weight & 10 & $(11.2)$ \\
\hline Physician's recommendation & 5 & (5.6) \\
\hline \multicolumn{3}{|l|}{ Lifestyle factors } \\
\hline Decreased food intake by mother & 6 & $(6.7)$ \\
\hline The mother's hair started falling out & 2 & $(2.2)$ \\
\hline Breastfeeding was affecting the mother's shape/body image & 1 & $(1.1)$ \\
\hline \multicolumn{3}{|l|}{ Medical factors } \\
\hline Health problems related to the mother (maternal illness/medication use, etc.) & 8 & (9) \\
\hline Became pregnant or wanted to become pregnant again & 5 & (5.6) \\
\hline Child health problem & 0 & (0) \\
\hline \multicolumn{3}{|l|}{ Milk-pumping factors } \\
\hline Pumping milk difficult/time consuming, etc. & 4 & $(4.5)$ \\
\hline \multicolumn{3}{|l|}{ Infant's self-weaning factors } \\
\hline Refused to feed & 19 & $(21.3)$ \\
\hline Began to bite & 5 & (5.6) \\
\hline \multicolumn{3}{|l|}{ Work related factors } \\
\hline Had to return to work & 14 & $(15.7)$ \\
\hline Maternity leave not long enough to develop breastfeeding schedule/habit & 24 & $(14.5)$ \\
\hline Insufficient time off during work days for breastfeeding & 20 & $(12)$ \\
\hline Home too far from work for breastfeeding & 9 & (5.4) \\
\hline Lack of work flexibility for breastfeeding time & 9 & (5.4) \\
\hline Lack of nursery at or close to work & 8 & $(4.8)$ \\
\hline Could not or did not want to pump or breastfeed at work & 8 & (4.8) \\
\hline Problems related to workplace & 4 & (2.4) \\
\hline Other reasons & 4 & (2.4) \\
\hline Other factors & 3 & (3.4) \\
\hline
\end{tabular}

breastfeeding knowledge scores were more likely to practice exclusive breastfeeding for 6 months. The higher exclusive breastfeeding rate in the U.A.E. and Saudi Arabia, compared to the U.S.A., could be further explained by the fact that maternity leave is longer in the U.A.E. and Saudi Arabia than in the U.S.A. and that maternity leave is granted with full salary, unlike in the U.S.A [26]. The latter differences could be due to strong family support in the U.A.E., 
Table 7 Factors that affect exclusive breastfeeding (EBF) practices among participants

\begin{tabular}{|c|c|c|c|c|c|c|c|}
\hline \multirow[t]{2}{*}{ Variable } & No EBF & EBF & \multirow[t]{2}{*}{$\overline{p \text {-value }}$} & \multirow[t]{2}{*}{ Variable } & \multirow{2}{*}{$\begin{array}{l}\text { No EBF } \\
\text { Number (\%) }\end{array}$} & EBF & \multirow[t]{2}{*}{$p$-value } \\
\hline & Number (\%) & Number (\%) & & & & Number (\%) & \\
\hline \multicolumn{3}{|l|}{ Age (in years) } & \multirow[t]{7}{*}{0.362} & \multirow{2}{*}{$\begin{array}{l}\text { Last child gestational age at } \\
\text { delivery }\end{array}$} & & & \multirow[t]{4}{*}{0.027} \\
\hline $18-24$ & $13(72.2)$ & $5(27.8)$ & & & & & \\
\hline $25-29$ & $58(69.9)$ & $25(30.1)$ & & \multirow{2}{*}{$\begin{array}{l}<37 \text { weeks } \\
\geq 37 \text { weeks }\end{array}$} & 36 (85.7) & $6(14.3)$ & \\
\hline $30-34$ & $50(67.6)$ & $24(32.4)$ & & & $123(68.7)$ & $56(31.3)$ & \\
\hline $35-39$ & $32(78)$ & $9(22)$ & & \multicolumn{2}{|l|}{ Mode of delivery of last child } & & \multirow[t]{3}{*}{0.550} \\
\hline $40-44$ & $7(100)$ & $0(0)$ & & Vaginal delivery & $91(70.5)$ & $38(29.5)$ & \\
\hline$\geq 45$ & $0(0)$ & $0(0)$ & & Caesarian section & $69(74.2)$ & $24(25.8)$ & \\
\hline \multicolumn{2}{|l|}{ Education background } & & \multirow[t]{4}{*}{0.814} & \multirow{2}{*}{$\begin{array}{l}\text { Healthcare provider explained the } \\
\text { importance of breastfeeding during } \\
\text { antenatal visits for last pregnancy }\end{array}$} & & & \multirow[t]{4}{*}{0.482} \\
\hline Primary school or lower & $1(100)$ & $0(0)$ & & & & & \\
\hline Secondary school & $29(70.7)$ & $12(29.3)$ & & Yes & $124(70.9)$ & $51(29.1)$ & \\
\hline University or higher & $129(71.7)$ & $51(28.3)$ & & No & $35(76.1)$ & $11(23.9)$ & \\
\hline \multicolumn{2}{|l|}{ Employed } & & \multirow[t]{4}{*}{0.004} & \multirow{2}{*}{$\begin{array}{l}\text { Healthcare provider explained the } \\
\text { importance of breastfeeding after } \\
\text { delivery of last child }\end{array}$} & & & \multirow[t]{4}{*}{0.631} \\
\hline No & $100(65.8)$ & $52(34.2)$ & & & & & \\
\hline Yes & $60(84.5)$ & $11(15.5)$ & & Yes & $133(72.3)$ & $51(27.7)$ & \\
\hline Self-employed & $0(0)$ & $0(0)$ & & No & $26(68.4)$ & $12(31.6)$ & \\
\hline \multicolumn{2}{|l|}{ Employment sector } & & \multirow[t]{3}{*}{0.052} & \multirow{2}{*}{$\begin{array}{l}\text { Healthcare provider explained } \\
\text { the appropriate practices of } \\
\text { breastfeeding for last child }\end{array}$} & & & 0.849 \\
\hline Private & $35(77.8)$ & $10(22.2)$ & & & & & \\
\hline Public & $23(95.8)$ & $1(4.2)$ & & Yos & $121(712)$ & $19(288)$ & \\
\hline $\begin{array}{l}\text { Entitled to breastfeeding hours } \\
\text { by employer }\end{array}$ & & & 0.112 & No & $37(72.5)$ & $14(27.5)$ & \\
\hline Yes & $46(80.7)$ & $11(19.3)$ & & Past breastfeeding experience & & & 0.168 \\
\hline No & $11(100)$ & $0(0)$ & & No other children & $52(76.5)$ & $16(23.5)$ & \\
\hline Living with husband and children only & & & 0.048 & No & $12(85.7)$ & $2(14.3)$ & \\
\hline Yes & $130(68.4)$ & $60(31.6)$ & & Yes & $91(66.9)$ & $45(33.1)$ & \\
\hline No (Living with relatives) & $24(88.9)$ & $3(11.1)$ & & Past exclusive breastfeeding & & & 0.000 \\
\hline $\begin{array}{l}\text { No (Separated/ Divorced/ } \\
\text { Widowed) }\end{array}$ & $3(100)$ & $0(0)$ & & No other children & $51(78.5)$ & $14(21.5)$ & \\
\hline Number of housemaids or nannies & & & 0.156 & No & $54(85.7)$ & $9(14.3)$ & \\
\hline 0 & $99(67.8)$ & $47(32.2)$ & & Yes & $49(56.3)$ & $38(43.7)$ & \\
\hline 1 & $41(82)$ & $9(18)$ & & Offered readymade formula in & & & 0.001 \\
\hline$>1$ & $11(73.3)$ & $4(26.7)$ & & & & & \\
\hline Monthly family income (in AED) & & & 0.209 & Yes & $72(84.7)$ & $13(15.3)$ & \\
\hline$<15,000$ & $68(77.3)$ & $20(22.7)$ & & No & 84 (63.2) & $49(36.8)$ & \\
\hline
\end{tabular}

$71(65.7) \quad 37(34.3)$

$15(71.4) \quad 6(28.6)$

0.151

$56(78.9) \quad 15(21.1)$

$95(66.9) \quad 47(33.1)$

$9(90) \quad 1(10)$

Gender of last child

Male

Female
$87(79.1) \quad 23(20.9)$

$67(63.2) \quad 39(36.8)$
Table 7 Factors that affect exclusive breastfeeding (EBF) practices among participants (Continued)

Healthcare provider explained the appropriate practices of reastfeeding for last child

$$
\begin{array}{ll}
124(70.9) & 51(29.1) \\
35(76.1) & 11(23.9)
\end{array}
$$$$
133(72.3) \quad 51(27.7)
$$$$
26(68.4) \quad 12(31.6)
$$

especially from mothers and mothers-in-law; this support was found to have a major effect on breastfeeding knowledge in our study. In addition, women who lived with their relatives had better breastfeeding knowledge and attitudes, and this could further explain the differences observed. On the other hand, the higher exclusive breastfeeding rates in Uganda could be due to their infant feeding tradition and culture: in some parts of Uganda, breastfeeding is considered the only acceptable way to feed an infant [27], and in other parts, women cannot afford formula milk and instead adopt breastfeeding [25]. 
Table 8 Multivariate logistic regression for the predictors associated with exclusive breastfeeding $(n=196)$

\begin{tabular}{|c|c|c|c|c|c|c|}
\hline$\underline{\text { Variables }}$ & Number & Coefficient & Standard Error & Adjusted $\mathrm{OR}^{\mathrm{a}}$ & $\left(95 \% \mathrm{Cl}^{\mathrm{b}}\right)$ & $p$-value \\
\hline \multicolumn{7}{|c|}{ Living with husband and children only } \\
\hline Yes & 171 & & & 1 & & \\
\hline No (Living with relatives) & 25 & -1.58036 & 0.69742 & 0.21 & $(0.05,0.81)$ & 0.0235 \\
\hline \multicolumn{7}{|c|}{ Past exclusive breastfeeding experience } \\
\hline No other children & 57 & -1.08063 & 0.44158 & 0.34 & $(0.14,0.80)$ & 0.0144 \\
\hline No & 57 & -1.46617 & 0.47043 & 0.23 & $(0.09,0.58)$ & 0.0018 \\
\hline Yes & 82 & & & 1 & & \\
\hline \multicolumn{7}{|c|}{ Given readymade formula in hospital } \\
\hline Yes & 77 & -1.12242 & 0.40437 & 0.33 & $(0.15,0.72)$ & 0.0055 \\
\hline No & 119 & & & 1 & & \\
\hline \multicolumn{7}{|l|}{ Gender of last child } \\
\hline Male & 101 & & & 1 & & \\
\hline Female & 95 & 0.88259 & 0.36800 & 2.42 & $(1.18,4.97)$ & 0.0165 \\
\hline Breastfeeding knowledge score & 196 & 0.22396 & 0.092921 & 1.25 & $(1.04,1.50)$ & 0.0159 \\
\hline \multicolumn{7}{|l|}{ Employment status } \\
\hline No & 135 & & & 1 & & \\
\hline Yes & 61 & -1.22911 & 0.45997 & 0.29 & $(0.12,0.72)$ & 0.0075 \\
\hline
\end{tabular}

${ }^{\mathrm{a} O R}$ Odds Ratio

${ }^{\mathrm{b}} \mathrm{Cl}$ Confidence Interval

Another factor that was found to be important in predicting exclusive breastfeeding in our study was whether mothers were offered readymade liquid formula in the hospital. The mothers who were offered readymade formula liquid while in hospital were less likely to exclusively breastfeed for 6 months. The latter could explain the difference in exclusive breastfeeding rates at 6 months between our study and Saudi Arabia [8], where $41.7 \%$ of the mothers in our study (compared with 66.7\% in Saudi Arabia) were offered ready-made liquid formula in the hospital. This might reflect the Baby-Friendly approach practiced in U.A.E. hospitals. Interestingly, it was also found in our study that female infants were more likely to be exclusively breastfed for 6 months compared to male infants, which could be explained by the cultural infant feeding practices seen in some areas in the Middle East [28].

According to the participants in our study, the most important reason for initiating breastfeeding was child health (89.8\%), followed by religious background (37\%). This finding was similar to the comparable findings in a study in Saudi Arabia, wherein the main reasons were identical: child health $(43.7 \%)$, followed by religious background (17.2\%) [20]. These similarities might be explained by the fact that these two countries have similar cultures, beliefs, and religion. Specifically, the connection between breastfeeding and religious tradition is most likely related to the Islamic teachings in the Holy Quran, which state, "And mothers shall breastfeed their children for two whole years, for those who desire to complete the appropriate duration of breastfeeding" [29].

Among women who stopped breastfeeding, breastfeeding was stopped at a mean age of 7.1 \pm 5.4 months in our study, which was slightly earlier than that in a study in Saudi Arabia $(8.7 \pm 7.8)$ [8]. The most common reason given for stopping breastfeeding in our study was decreased breast milk production (76.4\%), which corroborates findings in other studies $[8,30,31]$. It is possible, however, that in many cases, decreased breast milk production was perceived rather than real, as some other studies have found. [32] These other studies' results could mean that the women mistake normal infant behaviour of frequent feeding and waking at night as evidence of hunger, which is a socially acceptable reason for stopping breastfeeding. The second most common reason found in our study for stopping breastfeeding was the baby seeming hungry or unsatisfied after feedings (33.3\%). Work related problems were the second most common reason in a study in Saudi Arabia (38.5\%) [8]. Collectively, however, $67.4 \%$ of the participants in our study reported that work related problems were involved in the decision to stop breastfeeding and that among these, insufficient maternity leave was the most common (14.5\%). In our study, it was found that mothers who were employed were less likely to practice exclusive breastfeeding for 6 months, which is consistent with the findings of several studies [33, 34]. Other studies have shown that 


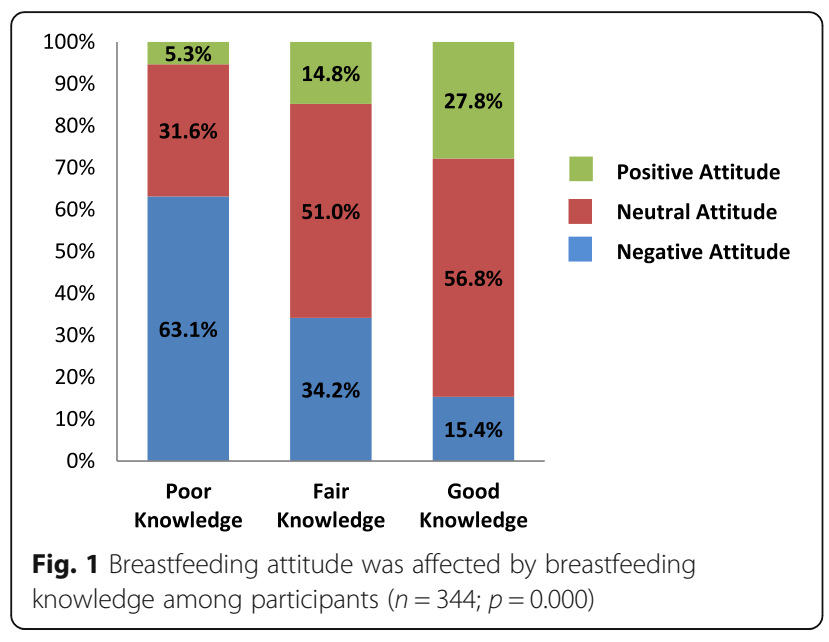

inadequate comprehensive maternity leave policies, lack of child care facilities at or near the workplace, rigid time schedules that do not allow for nursing breaks, lack of facilities providing privacy for breast-pumping, and absence of facilities for the refrigeration of pumped breast milk are among the factors that affect breastfeeding practice among working mothers $[35,36]$. Maternity leave for working mothers in the U.A.E. is very well outlined; mothers are entitled to 60 days' leave with full salary, which is also the case in Saudi Arabia. However, in Saudi Arabia, maternity leave can also be extended up to 3 years at $25 \%$ of the employee's salary [37]. The effect of these factors is likely to be the reason why most of our participants had shifted to formula feeding by 6 months (89.4\%), a proportion similar to that in a study in Saudi Arabia (91.7\%) [8].

Most participants intended to breastfeed future children (92.8\%), as in two Saudi Arabian studies (90.1\%) [8, 38]. These similarities could be explained by the similarity between the cultures and beliefs of these two countries. Another study has shown that such an attitude is

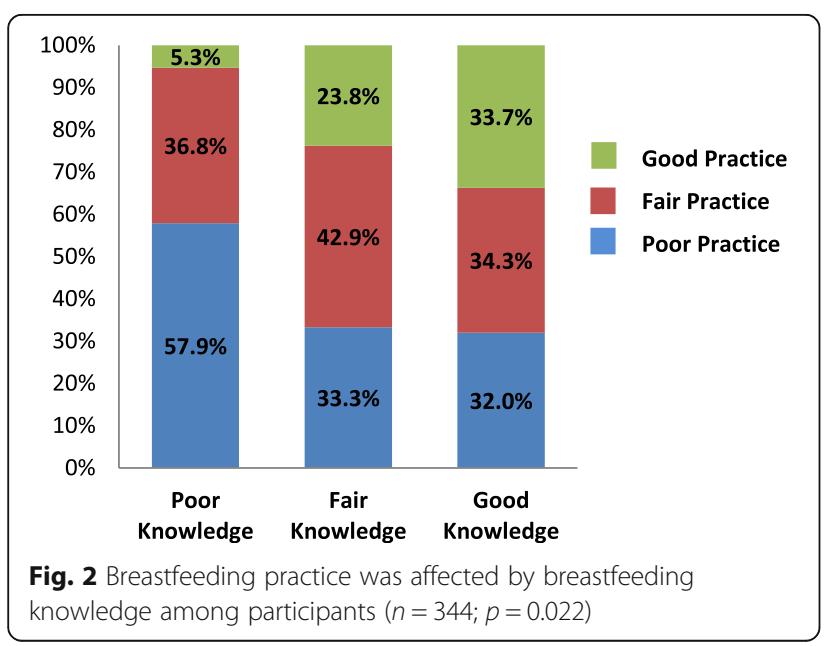

one of the strongest predictors of breastfeeding initiation and duration [31].

Most participants (86\%) in our study were aware of the benefits of feeding colostrum to the child, as in two Saudi Arabian studies $(89.3 \%)$ [8, 39]. In contrast, $77 \%$ of the surveyed mothers from the district of Rajasthan, India, discarded their colostrum [40]; this finding is similar to those recently reported in other parts of India where $60 \%$ of the studied women still discard colostrum [41]. These differences could be explained by the differences between the cultures and beliefs of the U.A.E. and these Indian regions.

Factors that may limit the generalization of our findings include cultural differences between women residing in Abu Dhabi and those residing outside Abu Dhabi; where there is a possible referral bias to our primary health care clinics as $80 \%$ of the sample had higher educational level. Furthermore, possible recall bias in responding to the questionnaire for older children could be another factor. Another limitation is that the questionnaire was long, which led to the failure to report complete data regarding some questions.

\section{Conclusions}

Although breastfeeding knowledge in the U.A.E. was generally good, breastfeeding practice was still suboptimal. Modifiable factors that was found to predict exclusive breastfeeding includes breastfeeding knowledge and mothers' employment status. The most common reasons for stopping breastfeeding were insufficient breast milk production and the baby seeming unsatisfied or hungry after feeding. Therefore, healthcare providers should provide breastfeeding education to all women during their antenatal follow-up visits, especially women with low educational qualifications and no past breastfeeding experience. Solutions should be provided to overcome the barriers to breastfeeding, especially for working mothers, by providing them with longer maternity leave and paid breaks to continue breastfeeding their children. Fortunately, a new law was recently established and passed in the U.A.E. that extends fully paid maternity leave from 2 months to 3 months, which is a step in the right direction.

\section{Additional files}

Additional file 1: Factors that affect breastfeeding knowledge among participants $(n=344)$. (DOCX $34 \mathrm{~kb})$

Additional file 2: Factors that affect breastfeeding attitudes among participants $(n=344)$. (DOCX $34 \mathrm{~kb})$

Additional file 3: Factors that affect breastfeeding practices among participants $(n=344)$. (DOCX $33 \mathrm{~kb})$

\section{Abbreviations}

AAP: American academy of pediatrics; AOR: Adjusted odds ratio; Cl: Confidence interval; EBF: Exclusive breastfeeding; FNC: Federal national council; IQR: Interquartile range; SD: Standard deviation; SKMC: Sheikh Khalifa medical City; SPSS: Statistical package for social sciences; U.A.E.: United Arab Emirates; U.S.A.: United States of America; WHO: World health organization 


\section{Acknowledgements}

We would like to express our gratitude and appreciation to the following people: Dr. Waleed Beshya and Dr. Anas Beshya (Education Institute at SKMC) for their contributions to the conception and design of the study; the charge nurses and staff in all the primary healthcare clinics involved in our study for their endless support during the study period; Dr. Ali Al-Binali (Department of Child Health, College of Medicine, King Khalid University) for providing us with his Arabic breastfeeding questionnaire; and Mrs. Eman Lahloub (Al Bateen Healthcare Centre) for her help with data entry. We would also like to thank ENAGO for their great efforts in editing this article.

\section{Availability of data and materials}

All data generated or analyzed during this study are included in this published article.

\section{Authors' contributions}

MIAK, SAN, AAA, ED, and MAF contributed substantially to the conception and design of the study. AAA contacted Dr. Ali Al Binali to obtain a copy of the questionnaire that was used in his study. MIAK modified/designed the English questionnaire, ED and MAF reviewed it, and AAA translated it to Arabic. MIAK, SAN, and AAA collected and entered the data in excel sheets. MIAK, ED, MAF and JR analyzed and interpreted the data. MIAK drafted the manuscript and ED, MAF and JR revised it critically for important intellectual content. All the authors read and approved the final manuscript.

\section{Ethics approval and consent to participate}

The study was approved by the Institutional Review Board of Research Ethics Committee at Sheikh Khalifa Medical City (SKMC; REC-15.12.2014 [RS-340]). Informed consent forms were attached with each questionnaire for the participants to read and sign if they were willing to participate in the study.

\section{Consent for publication}

The authors hereby declare their consent for publication.

\section{Competing interests}

The authors declare that they have no competing interests.

\section{Publisher's Note}

Springer Nature remains neutral with regard to jurisdictional claims in published maps and institutional affiliations.

\section{Author details}

'Sheikh Khalifa Medical City (SKMC), P.O. Box: 51900, Abu Dhabi, United Arab Emirates. ${ }^{2}$ Ethraa Consultation and Training, P.O. Box: 32311, Dubai, United Arab Emirates.

\section{Received: 24 June 2017 Accepted: 14 May 2018}

Published online: 03 July 2018

\section{References}

1. Eidelman Al, Schanler RJ, Johnston M, Landers S, Noble L, Szucs K, et al. Breastfeeding and the use of human milk. Pediatrics. 2012;129:e827-41.

2. Kramer MS, Kakuma R. The optimal duration of exclusive breastfeeding: a systematic review. Switzerland: World Health Organization; 2002. http://www. who.int/nutrition/publications/optimal_duration_of_exc_bfeeding_review_ eng.pdf. Accessed 21 Sept 2014.

3. Butte NF, Lopez-Alarcon MG, Garza C. Nutrient adequacy of exclusive breastfeeding for the term infant during the first six months of life. Geneva, Switzerland: World Health Organization; 2002. http://apps.who.int/iris/ bitstream/10665/42519/1/9241562110.pdf. Accessed 21 Sept 2014.

4. WHO Media Centre Fact Sheet. Infant and young child feeding. World Health Organization, 2016. http://www.who.int/mediacentre/factsheets/fs342/en/. Accessed 15 Oct 2016.

5. Cai X, Wardlaw T, Brown DW. Global trends in exclusive breastfeeding. Int Breastfeed J. 2012;7:12.

6. Radwan H. Patterns and determinants of breastfeeding and complementary feeding practices of Emirati mothers in the United Arab Emirates. BMC Public Health. 2013;13:171.

7. Al Tajir GK, Sulieman HS, Badrinath P. Intragroup differences in risk factors for breastfeeding outcome in a multicultural community. J Hum Lact. 2006;22(1):39-47.
8. Al-Binali AM. Breastfeeding knowledge, attitude and practice among school teachers in Abha female educational district, southwestern Saudi Arabia. Int Breastfeed J. 2012;7:10

9. Salem O. FNC passes mandatory breastfeeding clause for child rights law. The National UAE 2014. http://www.thenational.ae/uae/government/fnc-passesmandatory-breastfeeding-clause-for-child-rights-law. Accessed 21 Sept 2014.

10. The National UAE staff. New law extends maternity leave for Abu Dhabi government employees. The National UAE. 2016. http://www.thenational.ae/ uae/government/new-law-extends-maternity-leave-for-abu-dhabigovernment-employees. Accessed 20 Dec 2016.

11. Bell J, Webster N. UAE workers push for longer maternity leave at private firms. The national UAE. 2016. http://m.thenational.ae/uae/uae-workerspush-for-longer-maternity-leave-at-private-firms. Accessed 30 May 2017.

12. Creative Research Systems. Sample size calculator. 2012. https:/www. surveysystem.com/sscalchtm. Accessed 21 Sept 2014.

13. Newcombe RG. Two sided confidence intervals for the single proportion: comparison of seven methods. Stat Med. 1998;17:857-72.

14. Domburg R, Hoeks S, Kardys I, Lenzen M, Boersma E. Tools and techniquesstatistics: how many variables are allowed in the logistic and cox regression models? Eurolntervention. 2014;9(12):1472-3.

15. Peduzzi $\mathrm{P}$, Concato J, Kemper E, Holford TR, Feinstein AR. A simulation study of the number of events per variable in logistic regression analysis. J Clin Epidemiol. 1996:49(12):1373-9.

16. VassarStats: Website for Statistical Computation, The Confidence Interval of a Proportion. 2018. http://vassarstats.net/. Accessed 7 Feb 2018.

17. World Health Organization/UNICEF. Ten steps to successful breastfeeding. http://www.unicef.org/newsline/tenstps.htm. Accessed 15 Oct 2016.

18. World Health Organization. Breastfeeding key to saving children's lives. http:// www.who.int/mediacentre/news/notes/2010/breastfeeding_20100730/en/. Accessed 15 Oct 2016

19. Naylor AJ. Baby-friendly hospital initiative: protecting, promoting, and supporting breastfeeding in the twenty-first century. Pediatr Clin North Am. 2001;48(2):475-83.

20. Al-Binali AM. Knowledge, attitude and practice of breast-feeding among female health care workers in tertiary care hospitals. Med J Cairo Univ. 2012;80(1):159-64.

21. Al-Hreashy FA, Tamim HM, Al-Baz N, Al-Kharji NH, Al-Amer A, Al-Ajmi H, et al. Patterns of breastfeeding practice during the first 6 months of life in Saudi Arabia. Saudi Med J. 2008;29(3):427-31.

22. Li R, Zhao Z, Mokdad A, Barker L, Grummer-Strawn L. Prevalence of breastfeeding in the United States: the 2001 National Immunization Survey. Pediatrics. 2003;111(Supplement 1):1198-201.

23. Philipp BL, Malone KL, Cimo S, Merewood A. Sustained breastfeeding rates at a US baby-friendly hospital. Pediatrics. 2003;112(3):e234-6.

24. Petit Al. Perception and knowledge on exclusive breastfeeding among women attending antenatal and postnatal clinics: a study from Mbarara hospital-Uganda, august 2008. Dar Es Salaam Medical Student's Journal. 2010;16(1):27-30.

25. Bbaale E. Determinants of early initiation, exclusiveness, and duration of breastfeeding in Uganda. J Health Popul Nutr. 2014;32(2):249-60.

26. Gilpin L. 10 things you need to know about maternity leave in the US TechRepublic http://www.techrepublic.com/article/10-things-you-need-toknow-about-maternity-leave-in-the-us/. Accessed 20 Dec 2016.

27. Engebretsen IMS, Moland KM, Nankunda J, Karamagi CA, Tylleskär H, Tumwine JK. Gendered perceptions on infant feeding in eastern Uganda: continued need for exclusive breastfeeding support. Int Breastfeed J. 2010;5:13.

28. Galal O. Child feeding patterns in the Middle East. Saudi I Gastroenterol. 1995; 1(3):138-44.

29. Al-Jassir M, Moizuddin SK, Al-Bashir B. A review of some statistics on breastfeeding in Saudi Arabia. Nutr Health. 2003;17(2):123-30.

30. El Mouzan MI, Al Omar AA, Al Salloum AA, Al Herbish AS, Qurachi MM. Trends in infant nutrition in Saudi Arabia: compliance with WHO recommendations. Ann Saudi Med. 2009;29(1):20-3.

31. Meedya S, Fahy K, Kable A. Factors that positively influence breastfeeding duration to 6 months: a literature review. Women Birth. 2010;23(4):135-45.

32. Walker M. Core Curriculum for Lactation Consultant Practice. London: Jones and Bartlett; 2002.

33. Setegn T, Belachew T, Gerbaba M, Deribe K, Deribew A, Biadgilign S. Factors associated with exclusive breastfeeding practices among mothers in Goba district, south East Ethiopia: a cross-sectional study. Int Breastfeed J. 2012;7:17. 
34. Tan KL. Factors associated with exclusive breastfeeding among infants under six months of age in peninsular Malaysia. Int Breastfeed J. 2011;6:2.

35. Khassawneh M, Khader Y, Amarin Z, Alkafajei A. Knowledge, attitude and practice of breastfeeding in the north of Jordan: a cross-sectional study. Int Breastfeed J. 2006;23:17.

36. Barber-Madden R, Petschek MA, Paker J. Breastfeeding and the working mother: barriers and intervention strategies. J Public Health Policy. 1987;8(4):531-41.

37. Ministry of Civil Service. Vacation rules and regulation (article 22). Ministry of Civil Service, Saudi Arabia. http://www.mcs.gov.sa/InformationCenter/News/ MinistryNews/Pages/default.aspx. Accessed 15 Oct 2016.

38. Al-Madani M, Vydelingum V, Lawrence J. Saudi mothers' expected intentions and attitudes toward breast-feeding. Infant Child Adolesc Nutr. 2012;2(3):187-98.

39. Al-Jassir MS, El-Bashir BM, Moizuddin SK, Abu-Nayan AA. Infant feeding in Saudi Arabia: mothers' attitudes and practices. East Mediterr Health J. 2006; 12(1-2):6-13.

40. Singh MB, Haldiya KR, Lakshminarayan J. Infant feeding and weaning practices in some semi-arid rural area of Rajasthan. J Indian Med Assoc. 1997;95(11):576-8.

41. Patro S, Nanda S, Sahu R. Infant feeding practices of Paroja, a tribal community of Orissa. Stud Home and Commun Sci. 2012;6(1):21-5.

Ready to submit your research? Choose BMC and benefit from:

- fast, convenient online submission

- thorough peer review by experienced researchers in your field

- rapid publication on acceptance

- support for research data, including large and complex data types

- gold Open Access which fosters wider collaboration and increased citations

- maximum visibility for your research: over $100 \mathrm{M}$ website views per year

At BMC, research is always in progress.

Learn more biomedcentral.com/submissions 